\title{
Preliminary research for using Rene 41 in confectioning extrusion dies
}

\author{
M. Schwartz ${ }^{1,2}$, R. Ciocoiu ${ }^{1}$, D. Gheorghe ${ }^{1}$, G. Jula ${ }^{3}$ \& I. Ciucă ${ }^{1}$ \\ ${ }^{1}$ Politehnica University Bucharest, Romania \\ ${ }^{2}$ TRIP MATERIALS INC, Switzerland \\ ${ }^{3}$ S.C. LAROMET S.A., Romania
}

\begin{abstract}
The dies used for copper/brass hot extrusion made of tool steels failed after a small number of runs. The die must be either refurbished (reconditioned) either discarded or replaced by a new die. These results are not satisfactory for a good production, so we took into account a new alloy to use for confectioning the dies. Before the first die was readily made, an experiment was performed to justify the migration to this new alloy.

Heating cycles are performed to observe microstructure evolution in Rene 41. These heating cycles mimic the usage conditions of the die in service, except the stresses during extrusion. The alloy at specific number of cycles is analyzed by optic and electron microscopy (SEM), X-ray diffraction analysis (XRD), Vickers microhardness investigations and dilatometric tests.

Minor changes occurred in the microstructure: $\mathrm{M}_{23} \mathrm{C}_{6}$ carbides appeared at grain boundary and depleted adjacent regions in alloying elements.

Keywords: Rene 41, extrusion, heating cycles, microstructure evolution.
\end{abstract}

\section{Introduction}

Usually, for hot extrusion two steels grades are used: H13 and H11. These tools have a usage limit at $600^{\circ} \mathrm{C}$, since above $500^{\circ} \mathrm{C}$ their microstructure changes [1]. These microstructural changes lead to die failure via several mechanisms thermal fatigue, wear, softening and creep [2].

Research performed on failed steel extrusion dies showed, in our case, the failure by softening caused by carbide coalescence and depletion of the matrix of the reinforcing element; the carbides [3]. 
Our attention was drawn by Rene 41, a nickel base superalloy used widely for high performance components in jet engines and gas turbines since this alloy retains its high strength up to maximum tests temperatures of $1093^{\circ} \mathrm{C}$, when microstructural instability was observed and the toughness of the material was affected and excellent oxidation resistance in the range $650-900^{\circ} \mathrm{C}[4,5]$.

Rene 41 is a precipitation hardening superalloy - the matrix, designated as the $\gamma$ phase, has a FCC structure and contains high concentrations of $\mathrm{Co}, \mathrm{Cr}$, and $\mathrm{Mo}$ [6]. The strengthening phase, denoted $\gamma^{\prime}$ also with a FCC crystal structure and a $\mathrm{Ni}_{3} \mathrm{Al}$ chemical formula, is a precipitate phase, often coherent with the matrix. Rene 41 owes its strength and stability both to the stable austenitic matrix, the gamma prime size and morphology and carbides - which are strongly affected by heat treatment [7]. In an optimally aged alloy the boundaries between $\gamma$ and $\gamma^{\prime}$ particles are a substantial barrier for dislocation movement [8].

Other phases which alter the alloy properties are unavoidable, most of them appear during aging in service. Our research followed the identification of these phases (if they form) during a simulated high temperature exposure and other microstructural changes to help us decide in adopting this alloy for our extrusion dies.

\section{Experimental procedures}

The alloys chemical composition, as provided by the producer, is presented in table 1 .

Table 1: Chemical composition of Rene 41.

\begin{tabular}{|c|c|c|c|c|c|c|c|c|c|}
\hline$\% \mathrm{Al}$ & $\% \mathrm{C}$ & $\% \mathrm{Co}$ & $\% \mathrm{Cr}$ & $\% \mathrm{Fe}$ & $\% \mathrm{Mn}$ & $\% \mathrm{Mo}$ & $\% \mathrm{Si}$ & $\% \mathrm{Ti}$ & $\% \mathrm{Ni}$ \\
\hline 1.47 & 0.04 & 10.4 & 18.6 & 3.6 & 0.04 & 9.3 & 0.10 & 3.3 & Bal. \\
\hline
\end{tabular}

Five samples with relative close dimensions are cut using a metallographic cutting machine. The samples, at room temperature, are inserted in a furnace preheated at $850^{\circ} \mathrm{C}$, placed on a $30 \mathrm{~mm}$ thick steel plate also preheated and held for 300 seconds. Then the samples are extracted from the furnace and left to cool in normal atmospheric conditions with one face placed on an insulating material. This procedure was repeated and samples are removed and analyzed after 20, 40, 60,80 and 100 heating cycles. The same face was always used for contact with the steel plate and insulated during cooling.

The samples were prepared accordingly for the investigations performed: optic microscopy, scanning electron microscopy (SEM), X-ray diffraction analysis (XRD) and microhardness tests. 


\section{Results and discussion}

\subsection{Dilatometric analysis}

The dilatometric analysis was performed to determine eventual transformations within the material. Figure 1 depicts the heating curve of the alloy with superimposed segments which helped to identify slope variation.

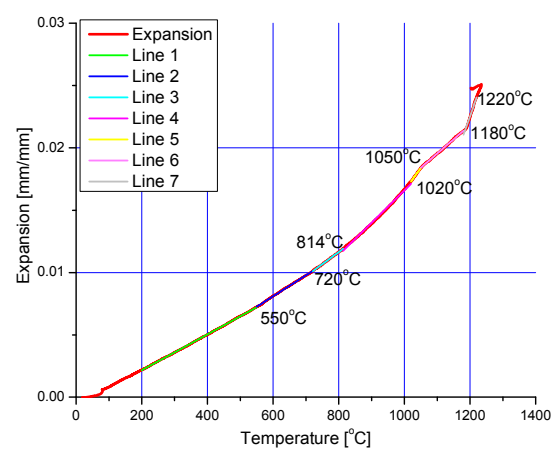

Figure 1: Dilatometric curve.

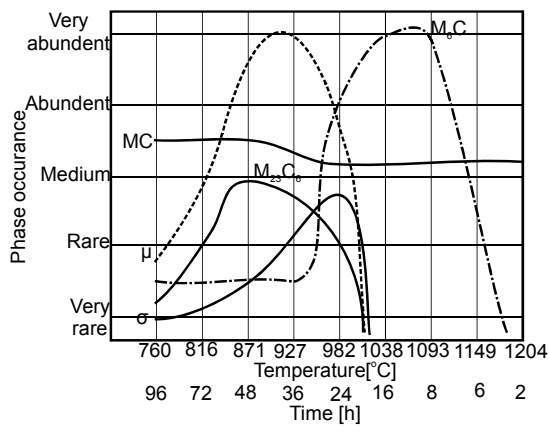

Figure 2: Phase occurrence in respect of exposure temperature and time [(adapted from [13]).

Studying the expansion curve for Rene 41, five transitions can be observed. The first, at around $550^{\circ} \mathrm{C}$, when $\gamma^{\prime}$ could start to precipitate. A debate for the presence of a transition at this temperature is also for Inconel 718 - which shows the same behavior at this temperature. Several authors [7-10] debate on the $\gamma^{\prime}$ precipitation starts temperature.

In a CuNi16Al5 alloy aged at $550^{\circ} \mathrm{C}$ Stobrawa and Rdzawski [11] suggests that the supersaturated solid solution starts by forming coherent spherical precipitates. In a Ni-Al-Ti system Doi et al. [12] show that at ageing at approx. $600^{\circ} \mathrm{C}$ the precipitate phase splits. The precipitates start to nucleate and grow as spherical precipitates, in further stages they tend to form a substructure and acquire a specific orientation; then the shape evolves from spherical to cubic and occupies specific sites in respect with the matrix.

The next shift, around $720^{\circ} \mathrm{C}$, carbides of the $\mathrm{M}_{23} \mathrm{C}_{6}$ could precipitate, since favorable conditions are met. From $800^{\circ} \mathrm{C}$ and above the $\gamma^{\prime}$ starts to precipitate up to $1020^{\circ} \mathrm{C}$, according to the diagram in fig. 2 . Above $1020^{\circ} \mathrm{C}$ an increase of the precipitated $\mathrm{M}_{23} \mathrm{C}_{6}$ is expected. Beyond $1080^{\circ} \mathrm{C}$ the dissolution of $\mathrm{M}_{23} \mathrm{C}_{6}$ could explain the slope change in the expansion curve. 


\subsection{Microstructure investigation}

\subsubsection{Optic microscopy}

At a plain visual inspection the samples exposed to the heating cycles did not show any cracks or clear distortions, only a dark and not very adherent layer of oxide was formed on the surface.

For optic microscopy studies the samples were prepared using standard metallographic procedure and etched with aqua regia for superalloys $(20 \mathrm{ml}$ $\left.\mathrm{HNO}_{3}+60 \mathrm{ml} \mathrm{HCl}\right)$.

The initial state of the alloy (fig. 3), shows grains with discontinuous grain boundaries and several carbides close to the grain boundary as well as within the grains. Particles within the grains appear larger. Titanium carbonitrides were also identified by their bronze color [14].

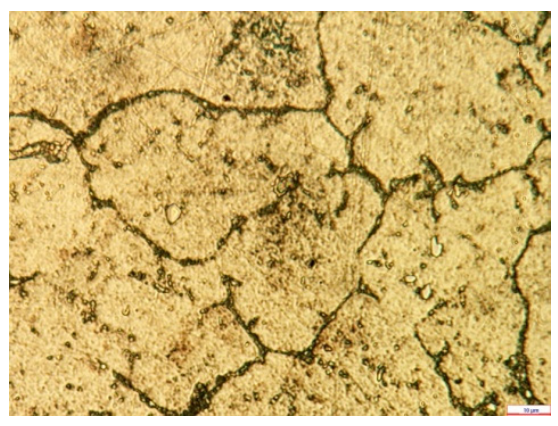

Figure 3: Optical micrograp initial state of the alloy.

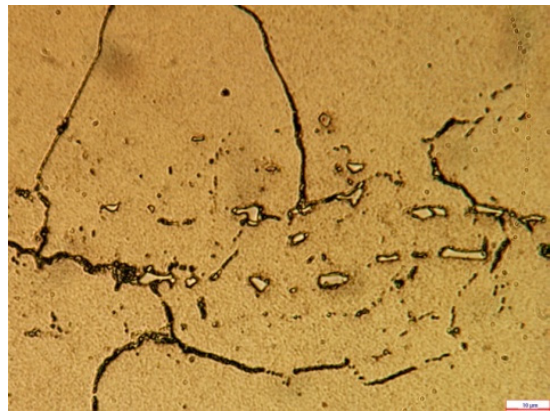

Figure 5: Optical micrograph -60 heating cycles.

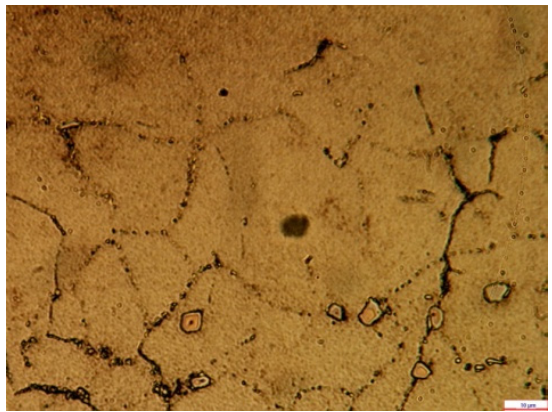

Optical micrograph -20 heating cycles.

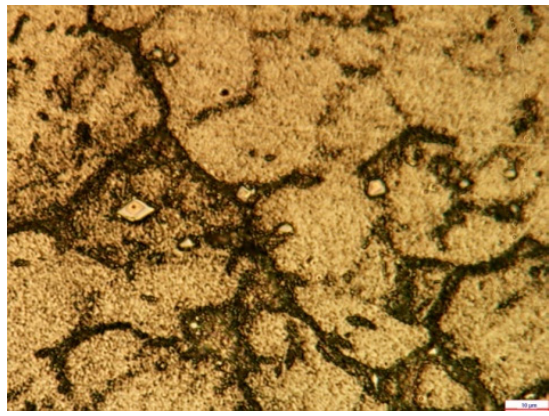

Figure 6:

Optical micrograph -100 heating cycles.

The microstructure for the cycled specimens (figs 4-6), shows discontinuous grain boundaries with carbides within grains and at grain boundaries. It is noticeable the grain boundary becomes thicker and becomes more susceptible to 
the metallographic etchant as the number of heating cycles increases. By metallographic aspect and its position at grain boundary it is to be expected the precipitation of $\mathrm{M}_{23} \mathrm{C}_{6}$ carbide - where $\mathrm{M}$ could be $\mathrm{Cr}$ or Mo, most probably $\mathrm{Cr}_{23} \mathrm{C}_{6}$. The precipitation of $\mathrm{M}_{23} \mathrm{C}_{6}$ carbides is caused by exposure at $850^{\circ} \mathrm{C}$. Carbon diffused and reacted either with chromium or molybdenum. Also, $\mathrm{M}_{6} \mathrm{C}$ carbides with cubic structure can form when exposed to $850^{\circ} \mathrm{C}$. These carbides tend to replace $\mathrm{M}_{23} \mathrm{C}_{6}$ if molybdenum is in higher concentration, $9.3 \% \mathrm{wt}$ in this case [15]. There is a possibility for $\mathrm{M}_{23} \mathrm{C}_{6}$ and $\mathrm{M}_{6} \mathrm{C}$ to coexist in a mixture at grain boundary.

Similar results are presented by Li [16]. Discrete $\mathrm{M}_{23} \mathrm{C}_{6}$, where $\mathrm{M}$ may be $\mathrm{Cr}$ or Mo, were found to have precipitated during aging at $760^{\circ} \mathrm{C}$ for $16 \mathrm{~h}$. A higher temperature and sufficient time were enough for formation of $\mathrm{M}_{23} \mathrm{C}_{6}$.

The grain size determination was performed according to ASTM E-112 specifications - processed images used for the determination of the grain size are depicted in fig. 7. The variation of the mean value is depicted by fig. 8 .

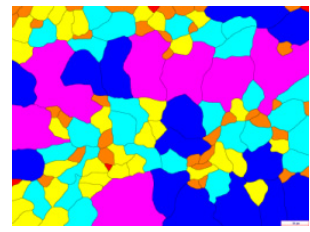

(a)

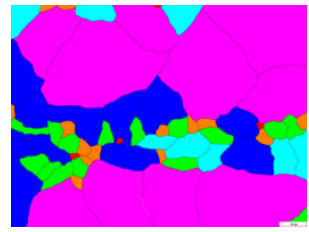

(b)

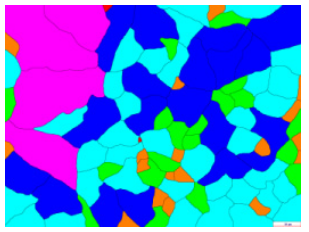

(c)

Figure 7: Processed images for determination of the grain size for (a) 20 cycles, (b) 60 cycles and (c) 100 cycles.

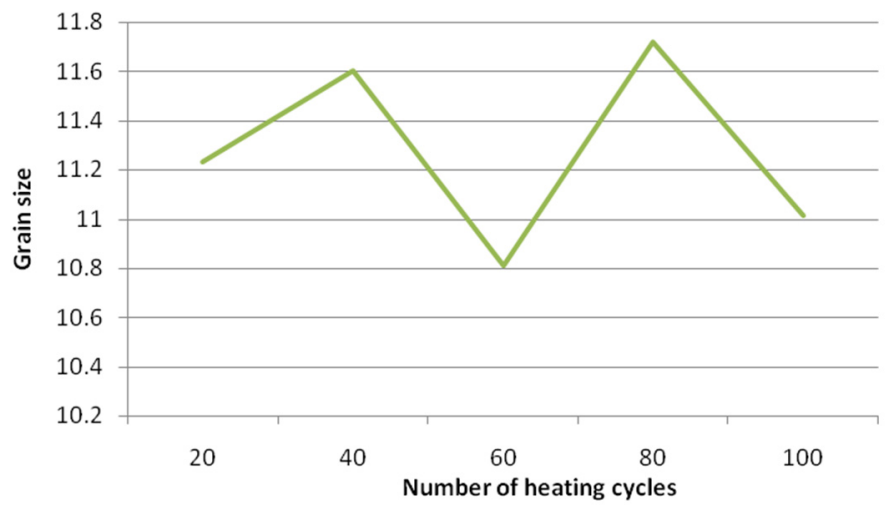

Figure 8: Grain size determined at different heating cycles.

No significant change in grain size is noticeable. 


\subsubsection{Scanning electron microscopy (SEM)}

Further SEM investigations revealed the austenitic matrix (the $\gamma$ phase) with the reinforcing phase $\left(\gamma^{\prime}\right)$ embedded within. The $\gamma^{\prime}$ phase can be distinguished at large magnifications, above $10^{4} \mathrm{X}$.

Large carbides are observable (figs 9(a)-(c)). They appear dark grey colored, polyhedral in shape, placed at grain boundary as well as within the matrix. These carbides are large, $8-9 \mu \mathrm{m}$ in length and 3-5 $\mu \mathrm{m}$ in width, dimensions measured in fig. 9(a). Aside these carbides appear other phases, light gray colored, $1 \mu \mathrm{m}$ in length and around $0.8 \mu \mathrm{m}$ in width, dimensions measured in fig. 9(a). By their aspect borides, carbides or carbonitrides of other heavy elements are to be expected.

Since the alloy is wrought, the amount of carbides is low.

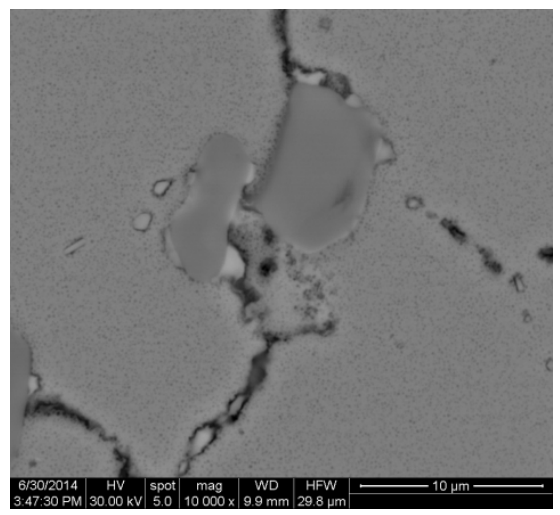

(a)

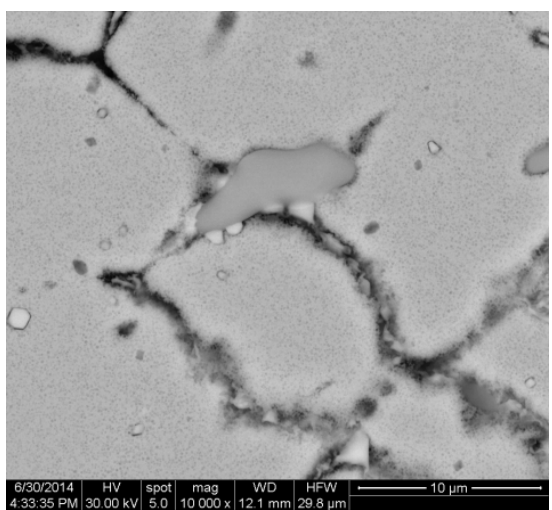

(b)

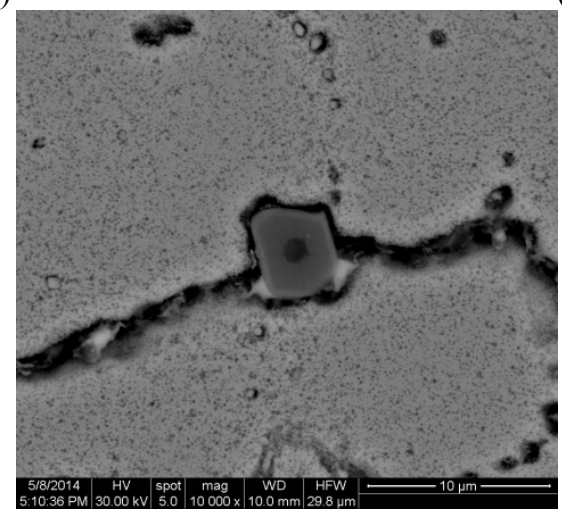

(c)

Figure 9: (a) SEM image of the alloy after 20 heating cycles. Carbides and the reinforcing phase $\gamma^{\prime}$ are observable; (b) SEM image of the alloy after 60 heating cycles. Carbides and the reinforcing phase $\gamma^{\prime}$ are observable along a thickening of the grain boundary is apparent; (c) SEM image of the alloy after 100 heating cycles. Carbides and the reinforcing phase $\gamma^{\prime}$ are observable. A depletion of the reinforcing phase $\gamma^{\prime}$ can be observed adjacent to grain boundary. 
In $\mathrm{Ni}$ base superalloys carbides of type $\mathrm{MC}, \mathrm{M}_{6} \mathrm{C}, \mathrm{M}_{23} \mathrm{C}_{6}$ and $\mathrm{M}_{7} \mathrm{C}_{3}$ are the most important types and in most cases they coexist jointly in the microstructure. The MC type is normally formed in the molten state while the later are formed by its breakdown and sequential reactions. The $\mathrm{M}_{23} \mathrm{C}_{6}$ and $\mathrm{M}_{7} \mathrm{C}_{3}$ types are formed at lower temperatures, ranging from 790 to $816^{\circ} \mathrm{C}$ while $\mathrm{M}_{6} \mathrm{C}$ is formed at intermediate temperature, 816 to $1038^{\circ} \mathrm{C}$. The $\mathrm{M}_{7} \mathrm{C}_{3}$ carbide is not usually found in superalloys [12].

No changes in $\gamma^{\prime}$ particles morphology or size was observed in current state of our research. The shape of the precipitates remains cuboidal. In fig. 9(c) a tendency to group or to align in chains can be inferred, the result to be expected would be a coalescence of these particles and coarsening of the reinforcing phase.
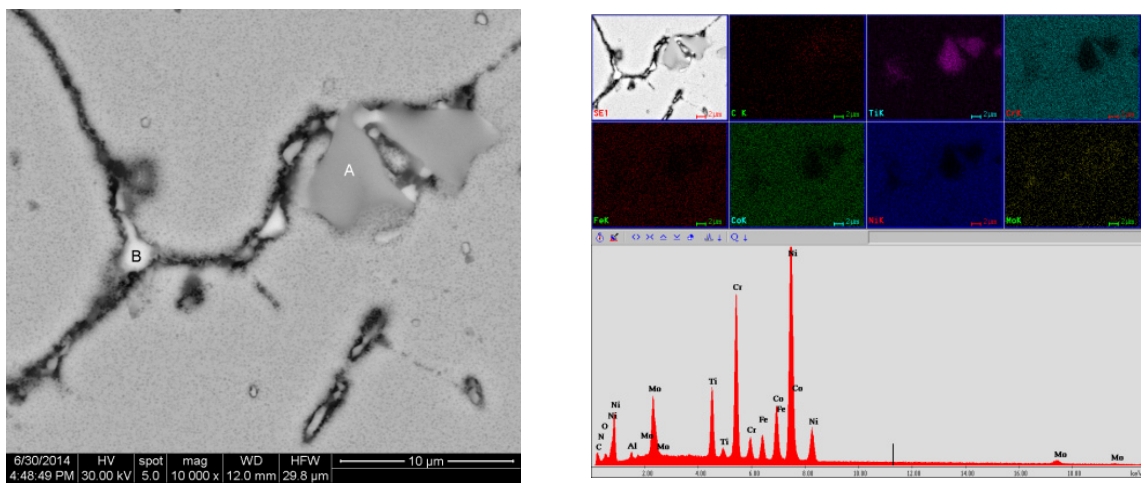

Figure 10: SEM image with elemental mapping and EDAX spectra.

By EDAX analysis a standard less EDAX ZAF quantification is performed on the two phases denoted "A" and "B" in fig. 10. The results are presented in tables 2 and 3 . The results show that the dark grey colored phases are titanium carbides while the light grey phases are molybdenum carbides.

Table 2: Chemical composition determined by EDAX on region denoted "A".

\begin{tabular}{|c|c|c|c|c|c|c|}
\hline$\% \mathrm{C}$ & $\% \mathrm{~N}$ & $\% \mathrm{Ti}$ & $\% \mathrm{Cr}$ & $\% \mathrm{Co}$ & $\% \mathrm{Ni}$ & $\% \mathrm{Mo}$ \\
\hline 20.74 & 5.18 & 36.85 & 2.42 & 1.28 & 4.59 & 28.27 \\
\hline
\end{tabular}

Table 3: Chemical composition determined by EDAX on region denoted "B".

\begin{tabular}{|c|c|c|c|c|c|}
\hline$\% \mathrm{C}$ & $\% \mathrm{Ti}$ & $\% \mathrm{Cr}$ & $\% \mathrm{Co}$ & $\% \mathrm{Ni}$ & $\% \mathrm{Mo}$ \\
\hline 15.29 & 9.05 & 11.69 & 5.37 & 17.16 & 39.78 \\
\hline
\end{tabular}

Other alloying elements are dissolved within the matrix forming the solid solution austenite (as can be seen in fig. 10). 
These phases appear in all samples. There are no changes in the microstructure of the alloy, except the precipitation of $\mathrm{Cr}_{23} \mathrm{C}_{6}$ on the grain boundary which becomes obvious at higher exposure times (fig. 9(c)). The grain boundaries become more pronounced and more susceptible to metallographic etchants. Also a slight discoloration at grain boundary can be observed in figs 9(a)-(c) which, most likely, is caused by the decrease in presence of the precipitate phase $\gamma^{\prime}$. By depleting the matrix of chromium at grain boundary the elements tied in the reinforcing phase tend to dissolve in the matrix, thus the decrease of volume fraction of the $\gamma$ '.

On the other hand, on former grain boundaries a high amount of $\gamma^{\prime}$ can be observed in fig. 9(c).

The $\mathrm{M}_{23} \mathrm{C}_{6}$ carbides, $\mathrm{Cr}_{23} \mathrm{C}_{6}$ in this case, forms in alloys starting with moderate chromium content - in this case the $\mathrm{Cr}$ content is around $18 \%$. It forms at low temperature service (or heat treatment) by degeneration of the MC type and from available carbon from the austenitic phase. Normally it precipitates at grain boundary but it can be found along twins and appear as irregular discontinuous particles. The $\mathrm{M}_{6} \mathrm{C}$ type form when $\mathrm{Mo}$ or $\mathrm{W}$ is higher than 6 at. \%. This type, stable at higher temperatures than $\mathrm{M}_{23} \mathrm{C}_{6}$ becomes of practical importance when placed at grain boundary since it can be used to control grain size. It appears in blocky form on grain boundaries and can form Widmanstätten structures.

The role of carbides is beneficial by tying elements that might lead to phase instability and they can strengthen the grain boundary by preventing sliding. Continuous grain boundary carbide (cellular) $\mathrm{M}_{23} \mathrm{C} 6$ or Widmanstätten pattern $\mathrm{M}_{6} \mathrm{C}$, are usually avoided to obtain the best ductility and rupture life. Since the high amount of chromium tied in $\mathrm{Cr}_{23} \mathrm{C}_{6}$ it is believed that the regions adjacent to these carbides are depleted of $\mathrm{Cr}$ and become susceptible to stress corrosion cracking [6]. When this type of carbide forms as a continuous film a heat treatment - resolutioning - is performed at $1038^{\circ} \mathrm{C}$ when the $\mathrm{M}_{6} \mathrm{C}$ type is reformed and the ductility of the material is restored.

\subsection{XRD analysis}

The diffractogram of all investigated samples is depicted in fig. 11. Since the matrix and the precipitated phase are coherent the peaks are almost perfectly overlapping, thus making the distinction very difficult. For an improvement in phase distinction an extraction of minor phases would be recommendable. The peaks are slightly shifted to the left which indicates a strain.

The lattice parameter for $\mathrm{Ni}_{3} \mathrm{Al}\left(\gamma^{\prime}\right)$ is $3.6080 \AA$ while for the matrix $(\gamma)$ $3.5805 \AA$. Considering the peaks obtained solely by diffraction from the matrix the lattice parameters are calculated. After 20 cycles the lattice parameter was estimated at $3.601_{2} \AA$. As the number of cycles increased 40, 60 and 100 the lattice parameter was found to be $3.600_{7}, 3.600_{5}$ and $3.600_{4} \AA$. The decrease of the lattice parameter value suggests a relaxation which could be produced by diffusion of atoms from the matrix. 


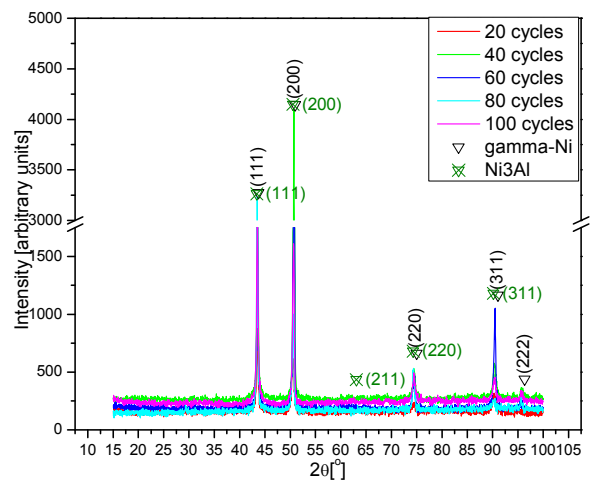

Figure 11: X-ray diffraction patterns for all samples and indexed peaks.

Using Scherrer's formula to estimate the mean apparent crystallite size, a mean value placed around $22 \mathrm{~nm}$ was calculated for all samples and no significant variation was noticed.

\subsection{Microhardness tests}

The micro hardness tests performed counted 10 tests/sample table 4 presents the important statistics. The microhardness tends to drop with increasing number of cycles until the 100 cycle value, which rises again (as presented in fig. 12).

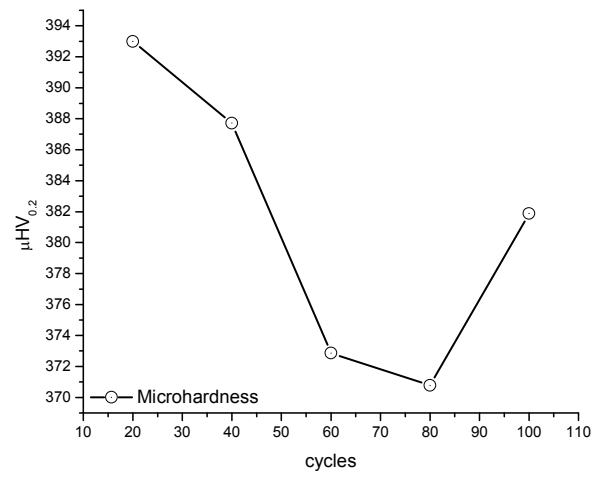

Figure 12: Microhardness variation in respect with number of heating cycles.

Referring to table 4, where the mean values and standard deviation are presented an important and significant drop in hardness values was detected after 60 cycles of heating and after 80 cycles the value did not change significantly. After 100 cycles the microhardness value increases again but the values show a wide spread so this increase cannot be stated as certain. Rather the microhardness would fall in the range of those determined at 60 and 80 cycles. 
Table 4: Microhardness statistics.

\begin{tabular}{|c|c|c|c|}
\hline No. of cycles & Mean & Median & $\begin{array}{c}\text { Standard } \\
\text { deviation }\end{array}$ \\
\hline 20 & 393 & 396 & 8.74 \\
\hline 40 & 388 & 388 & 12.03 \\
\hline 60 & 373 & 374 & 8.29 \\
\hline 80 & 370 & 374 & 14.78 \\
\hline 100 & 382 & 383 & 13.28 \\
\hline
\end{tabular}

\section{Conclusions}

The purpose of this experiment was to make a justified decision for the selection of the Ni base superalloy as material for the extrusion dies. Simulating only the temperature effects on the material the microstructure was investigated and the decision was taken by comparison with usual tool steel used in the factory [3].

The thermal cycles produced an effect similar to heat treatment.

Using optic and electronic microscopy the thermal stability of the alloy was confirmed, even in this unusual working regime. The grain size did not change, neither significant phase transformation occurred. The only aspect noticeable was the thickening of the grain boundary by formation and segregation of $\mathrm{Cr}_{23} \mathrm{C}_{6}$ as discontinuous particles. As long as the $\mathrm{Cr}_{23} \mathrm{C}_{6}$ carbide doesn't form as cellular structure, the critical location at grain boundary becomes beneficial increasing the rupture strength by impeding grain boundary sliding [17]. The ideal shape would be a zipper like shape [18].

By XRD analysis no formation of new phases could be detected. The peaks for the phases present overlap almost perfectly, a sign that the coherence between the matrix and the precipitate phase is still existent. Assuming the peaks resulted only from the matrix computations performed showed no significant variation for the crystallite size, only a decrease of the lattice parameter after 20 cycles. The relaxation was observed also during microhardness investigations, a significant drop was noticed after 40 cycles after which no significant variation occurred - similar with lattice parameter variation.

These results are viewed by comparison with the tool steel used. The life span of the die made of steel was short, about $4 \mathrm{t}$ of extruded material.

The steel die is used in copper extrusion, the copper billet heated at $850^{\circ} \mathrm{C}$. The die lasts for a total exposure at $850^{\circ} \mathrm{C}$ about $0.208 \mathrm{~h}$. Within this time the carbides of the steel grow and deplete the matrix causing the softening of the die and obviously its disposal.

In case of Rene 41 , even after 100 heating cycles $\left(8.3 \mathrm{~h}\right.$ exposure at $\left.850^{\circ} \mathrm{C}\right)$ minor changes occur within the microstructure. Although this service life is not a usual one for Rene 41, it promises great potential to be used for extrusion dies. Also, by enlarging the number of heating cycles an approximate time for resolutioning (heat treating) the die can be predicted. An appropriate heat treatment should remove the carbide film from the grain boundary and extend the die life. 
For an accurate extrapolation, the tool steel used for actual dies is currently subjected to the same heating regime and samples will be investigated accordingly.

\section{Acknowledgement}

These research results are obtained within the project entitled 'Materiale speciale destinate confectionarii matritelor pentru extrudarea la cald a cuprului si alamelor' (Special materials for hot extrusion dies for copper and brass), an effort from Politehnica University of Bucharest and LAROMET S.A.

\section{References}

[1] Grellier, A., Siaut, M., A New Hot Work Tool Steel For High Temperature and High Stress Service Conditions, 6th International Tooling Conference

[2] Arif, A. F. M., Sheikh, A. K. et al. (2003). "A study of die failure mechanisms in aluminum extrusion." Journal of Materials Processing Technology 134(3), pp. 318-328

[3] Schwartz, M., Ciocoiu, R. et al. (2014). "Failures of AISI H21 die in copper hot extrusion." Materials at High Temperatures 31(2), pp. 95-101

[4] Pierce, J.L., Zawada, L.P., Srinivasan, R., Tensile behavior of SiC/C and Rene' 41 following isothermal exposure and thermal fatigue, Journal of Materials Science, Vol. 35, Iss. 12, pp. 2973-2984, Doi 10.1023/ A: 1004778726935

[5] Kayacan, R., Varol, R., et al. (2004). "The effects of pre- and post-weld heat treatment variables on the strain-age cracking in welded Rene 41 components." Materials Research Bulletin 39(14-15), pp. 2171-2186

[6] ASM Specialty Handbook, Heat Resistant Materials, ASM International

[7] Li, J., Wang, H. M., Tang, H. B., Effect of heat treatment on microstructure and mechanical properties of laser melting deposited $\mathrm{Ni}$ base superalloy Rene 41, Materials Science and Engineering A 550 (2012), pp. 97-102

[8] Geddes, B., Leon, H., Huang, X., Superalloys, Alloying and Performance, ASM International, 2010

[9] Sundararaman, M., Mukhopadhyay, P., Banerjee, S., Precipitation of the $\gamma^{\prime}-\mathrm{Ni} 3 \mathrm{Nb}$ phase in two nickel base superalloys, Metall. Trans. 19A (1988), pp. $453-465$

[10] Sundararaman, M., Mukhopadhyay, P., Banerjee, S., in: E.-A. Loria (Ed.), Precipitation and Room Temperature Deformation Behaviour of Inconel 718, Superalloys 718, 625, 706 and various derivatives, TMS, 1994, pp. 419-440

[11] Strobawa, J.B., Rdzawski Z. M., Precipitation process of the Ni3Al phase in copper-based alloys, Journal of Achievements in Materials and Manufacturing Engineering, Vol. 15, Iss. 1-2 March - April, 2006, pp. $21-26$ 
[12] Doi, M., Miki, D., Moritani T. and Kozaki T., Gamma/Gamma - prime microstructure formed by phase precipitation of gamma-prime precipitates in a Ni-Al-Ti Alloy, Superalloys 2004, TMS

[13] Heat Treater's Guide: Practices and Procedures for Nonferrous Alloys, ed. H. Chandler, ASM International, 1996

[14] Gluck, J. V., Freeman, J. W., Effect of creep-exposure on mechanical properties of Rene 41, ASD Technical Report 61-73, June 1961

[15] Jena, A. K., Chaturvedi, M. C., J. Mater. Sci. 19 (1984), pp. 3121-3169

[16] Li, J., et al. Materials Science and Engineering A 550 (2012), pp. 97-102

[17] Donachie, M. J., Donachie, S. J., Superalloys, A Technical Guide, Second Edition, ASM International, 2002, pp. 30-38

[18] Aerospace Materials Handbook, Ed. S. Zhang, D. Zhao, CRC Press, 2013, ISBN 978-1-4398-7329-8, pp. 13-15 